Texas A\&M University-San Antonio

Digital Commons @ Texas A\&M University- San Antonio

8-2-2019

\title{
Humble Doctors, Healthy Patients? Exploring the Relationships Between Clinician Humility and Patient Satisfaction, Trust, and Health Status
}

Ho Phi Huynh

Texas A\&M University-San Antonio, Ho.Huynh@tamusa.edu

Amy Dicke-Bohmann

Texas A\&M University-San Antonio, Amy.Bohmann@tamusa.edu

Follow this and additional works at: https://digitalcommons.tamusa.edu/psyc_faculty

Part of the Medicine and Health Sciences Commons, and the Psychology Commons

\section{Repository Citation}

Huynh, Ho Phi and Dicke-Bohmann, Amy, "Humble Doctors, Healthy Patients? Exploring the Relationships Between Clinician Humility and Patient Satisfaction, Trust, and Health Status" (2019). Psychology Faculty Publications. 4.

https://digitalcommons.tamusa.edu/psyc_faculty/4

This Article is brought to you for free and open access by the College of Arts and Sciences at Digital Commons @ Texas A\&M University- San Antonio. It has been accepted for inclusion in Psychology Faculty Publications by an authorized administrator of Digital Commons @ Texas A\&M University- San Antonio. For more information, please contact deirdre.mcdonald@tamusa.edu. 
Humble Doctors, Healthy Patients? Exploring the Relationships Between Clinician Humility and Patient Satisfaction, Trust, and Health Status

\author{
Ho Phi Huynh, Ph.D. ${ }^{1}$ \\ Amy Dicke-Bohmann, Ph.D. \\ Texas A\&M University - San Antonio \\ ${ }^{1}$ Corresponding Author \\ Department of Science and Mathematics \\ One University Drive \\ San Antonio, TX 78224 \\ Email: hhuynh@tamusa.edu
}

\title{
To cite this paper:
}

Huynh, H., \& Bohmann, A. (2019). Humble doctors, healthy patients? Exploring the relationships between clinician humility and patient satisfaction, trust, and health. Patient Education and Counseling. doi: 10.1016/j.pec.2019.07.022 


\begin{abstract}
Objective: In medicine, numerous commentaries implore clinicians (e.g., physicians, physician assistants, nurse practitioners) to display more humility. However, given the complex power dynamics between patients and clinicians, one should not presume that patients desire and appreciate humble clinicians. This paper examines the relationship between clinician humility and patient outcomes, and aims to provide empirical evidence for the significance of clinician humility. Methods: In two studies, patients $(N=497)$ recalled their most recent visit to a clinician through an online survey platform (Qualtrics). Patients rated their clinician's humility, their satisfaction and trust with their clinician, and their health status. They also provided demographic information (e.g., gender, race, subjective SES), details about their clinician (e.g., gender, race, professional status) and information about their last medical visit with this clinician (e.g., purpose of visit, wait time during visit). Results: Through hierarchical multiple regression, we demonstrated that clinician humility positively predicted patient satisfaction, trust, and selfreport health (only in Study 2) above and beyond patient, clinician, and visit characteristics.
\end{abstract} Conclusion: The results demonstrated that clinician humility can predict important patient outcomes above and beyond objective characteristics of the medical interaction. Practice Implications: These findings may shape clinician-patient interactions by validating the pursuit of humility during medical encounters.

Keywords: humility; physician humility; clinician humility; clinician patient relationship; doctor patient relationship; patient satisfaction; trust; health status 
Humble Doctors, Healthy Patients? Exploring the Relationships Between Clinician Humility and Patient Satisfaction, Trust, and Health Status

\section{Introduction}

In medicine, numerous commentaries implore clinicians (e.g., physicians, physician assistants, nurse practitioners) to display more humility $[1,2,3]$. However, given the complex power dynamics between patients and clinicians [4], one should not presume that patients desire and appreciate humble clinicians. This paper addresses this gap in the literature by examining the relationship between clinician humility and patient outcomes.

Humility is a multidimensional virtue. Its intrapersonal component includes having an accurate view of one's strengths and weaknesses and an openness to new ideas and information. Its interpersonal component includes holding egalitarian beliefs and an other-focused orientation. In other words, humble people possess a secure sense of self that is not overinflated nor selfdebasing. This secure self enables people to understand their strengths and acknowledge their limitations, and be open to new information, even when that information counters what they already know. Additionally, humble people focus their attention on and find value in others [5].

Historically, humility has been perceived as an undesirable quality associated with weakness, self-abasement, and unworthiness [6]. However, modern psychologists have discovered evidence to the contrary. For example, researchers have found that humble people cooperate with others and avoid exploiting them even when the opportunity is there [7]. They also tend to be forgiving [8] and grateful [9]. Moreover, in light of an egocentric society [10], there is a recent, yet substantial, push for the examination and cultivation of humility in many domains (e.g., business and leadership [11]). However, the call for humility lacks empirical support from the patient care literature. 
The lone empirical paper to directly investigate humility in clinicians found that clinician humility positively predicted effective communication and subjective health [12]. However, these findings did not involve patients' perception of clinician humility. The researchers relied solely on independent coders to detect clinician humility by listening to audio recordings of medical interactions. Although this approach addresses the methodological paradox of self-report in humility measurement (i.e., humble people are unlikely to report as humble, while those who readily claim to be humble may not be very humble [13]), it disregards the critical interpersonal component of humility judgement [14]. In medical interactions, patients' perceptions of clinician humility may be the most consequential predictor of patient outcomes. In other words, the patient may not be concerned with whether the clinician thinks of him- or herself as humble nor whether a neutral observer thinks the clinician is humble; what may matter most to the patient is whether the patient thinks the clinician is humble. In the following, we address this critical gap in the literature by examining how clinician humility, as perceived by patients, may predict patient satisfaction, trust, and health status. These outcomes are essential markers of patients' preference for humble clinicians and are indicative of humble clinicians' effectiveness.

Patient satisfaction refers to care recipients' personal, subjective evaluations of the health care process $[15,16]$. Satisfied patients are more likely to adhere to the clinician's treatment recommendations and to pursue treatment with the same provider than unsatisfied patients [17]. Patients may be more satisfied with humble clinicians because of humble clinician's otherorientation and egalitarian beliefs. For example, when clinicians focus on their patients and value patients as partners in the process of care, they may be more likely to engage patients in motivational interviewing [18] or shared decision making [19]. These actions are likely to result in more patient satisfaction [20]. 
In addition to patient satisfaction, humble clinicians may engender more trust from their patients. Trust refers to patients' holistic beliefs on whether a clinician's words and actions are credible and reliable [21]. Patient trust predicts many important outcomes such as patient satisfaction, adherence, and loyalty [22]. Because humble clinicians know their own strengths and weaknesses, they may display their honesty regarding topics in which they have limited knowledge. This act may lead patients to appreciate the clinicians' honesty and integrity, which may lead them to trust the clinician more. Moreover, because humble clinicians are neither selfaggrandizing nor self-abasing, patients can trust their clinicians to not make misguided recommendations stemming from arrogance or incompetence.

Besides potentially influencing patient satisfaction and trust, humble clinicians may have healthier patients. One way to measure this potential downstream consequence of clinician humility is through patient-reported health status. These subjective evaluations reflect a holistic assessment of patients' health, as patients are likely to consider their physical, social, and mental health in their account [23]. Even though it only relies on patient self-report, it consistently predicts mortality, cardiovascular disease, and cost of care [24]. Patients may self-report as healthier under the care of humble clinicians than non-humble clinicians. For example, because humble clinicians value patients' contribution to the relationship, they are likely to seek patient input for treatment plans. This process is likely to lead to a treatment plan that addresses patients' biopsychosocial needs. In contrast, non-humble clinicians may see themselves as the unfailing expert, which may lead them to adopt a parental approach and value the biomedical model of care [25].

\subsection{Overview and Hypotheses:}


Two identical studies, using different samples, examined the relationship between clinician humility and patient outcomes. Study 1 employed a convenience sample of undergraduate students. We used this sample as an initial test of our hypotheses because it was easily accessible and cost effective. However, we recognize that results derived from student participants would likely be a conservative estimate of the outcomes found in the community. Thus in Study 2, we employed a large community sample recruited through a crowdsourcing network (Amazon Mechanical Turk) to replicate Study 1's findings. In both studies, we hypothesized that clinician humility will positively predict patient satisfaction, trust, and health status, above and beyond the predictive power of patient, clinician, and visit characteristics.

\section{Study 1}

\subsection{Method}

2.1.1 Participants. Undergraduate students $(N=136)$ at a regional university in Texas completed this study as partial fulfillment of a course requirement. Alternative options were available to students who prefer to not participate in research for credit (i.e., participation in research is voluntary). See Table 1 for demographics.

2.1.2 Measures. For means, standard deviations, and reliability (Cronbach's $\alpha$ ) for each

measure, see Table 2. Humility was measured using the Global Humility Subscale of the Relational Humility Scale [8]. Participants used a 5-point rating scale ranging from 1 (strongly disagree) to 5 (strongly agree) to evaluate their clinician. Samples items include: "This person is truly a humble person"; "Most people would consider this person a humble person."

Patient satisfaction was measured using the Short Assessment of Patient Satisfaction [26]. Participants responded to five statements using the following a 5-point rating scale: 0 - very dissatisfied, 1 - dissatisfied, 2 - neither satisfied nor dissatisfied, 3 - satisfied, 4 - very satisfied. 
Sample statements include: "How satisfied are you with the care you received from your doctor?"; "How satisfied were you with the effect of your treatment?"

Trust was measured using the interpersonal trust in patient-clinician relationships scale [27]. Participants responded to 11 items using a 7-point rating scale ranging from 1 (strongly disagree) to 7 (strongly agree). Sample items include: "If my doctor tells me something is so, then it must be true"; "I sometimes distrust my doctor's opinion and would like a second one" (reverse coded).

Patient health status was assessed using the Health Status Measure by UeroQuol Group [28]. Participants used a sliding scale from 0 ("worst state you can imagine") to 100 ("best state you can imagine") to indicate their health status.

Participants also answered demographic questions (i.e., age, gender, race/ethnicity, subjective SES, education, insurance status), questions about their clinician (i.e., gender, race, professional title, relationship length), and questions about the visit (i.e., (wait time, purpose of visit, elapsed time since visit). See Table 3 for a summary of participants' responses to these questions.

2.1.3 Procedures. Participants clicked on a web link that led them to an online questionnaire. Following consent procedures, participants answered questions about their last visit with a doctor (i.e., clinician). The majority of participants reported seeing a physician (79.4\%); fewer people reported seeing a nurse practitioner (11\%) and physician assistant (9.6\%).

Participants reported the purpose of their doctor visit and information about their doctor (e.g., gender, race/ethnicity). Then participants completed the main measures for the study. We presented measures for humility, patient satisfaction, trust, and health status in random order to 
avoid potential order effects. Lastly, participants reported their demographic information. On average, participants took 20.34 minutes $(S D=11.59)$ to complete the survey.

\subsection{Results}

2.2.1 Data Analysis Plan and Preliminary Analyses. Our goal was to examine the effects of clinician humility above and beyond the effects of demographic factors or visit features. Therefore, we employed hierarchical multiple regression and entered the predictor variables in four steps, running separate models for each outcome (satisfaction, trust, and subjective health): (1) Patient demographics (age, gender, race/ethnicity, SES, education, insurance status/type; (2) Clinician characteristics (gender, ethnicity, professional title, relationship length); (3) Visit features (purpose, wait time, elapsed time since visit); (4) clinician humility.

We examined the main assumptions for multiple regression prior to conducting the analyses. There were no univariate outliers [29] (all $z$-scores were below $+/-2.87$ ) and there were no multivariate outliers [30] (all Mahalanobis distance scores were below the critical Chi-Square value of $14.45, d f=3, \alpha=.001$ ). The highest variance inflation factor (VIF) value was 3.00, which is lower than the conservative benchmark of 5, suggesting that collinearity was not an issue. Additionally, the histogram of standardized residuals, the P-P plot, and the residual scatter plot supported the assumptions of normality, linearity, and homoscedasticity.

2.2.2 Main Results. We organized the main findings by dependent variable below. See Table 4 for a summary of variance accounted for $\left(R^{2}\right.$ and $\left.\Delta R^{2}\right)$.

Patient satisfaction. Results from step 1 indicated that no patient characteristics predicted patient satisfaction, $F_{(6,115)}=.41, p=.87$. In step 2 , no clinician characteristic predicted patient satisfaction, $F_{(4,111)}=1.19, p=.14$. In step 3 , wait time significantly accounted for additional 
variance in patient satisfaction, $\beta=-.26, p=.006 ; F_{(5,106)}=3.14, p=.01$. In step 4 , clinician humility significantly and positively explained additional variance in patient satisfaction, $\beta=.59$, $p=<.001 ; F_{(1,105)}=50.58, p<.001$.

Trust. Results from step 1 indicated that no patient characteristic predicted trust, $F_{(6,110)}=$ $.88, p=.51$. In step 2, relationship length with the clinician significantly explained additional variance in trust, $\beta=.24, p=.01 ; F_{(4,106)}=3.70, p=.007$. In step 3 , no visit characteristic significantly explained trust, $F_{(5,101)}=.87, p=.50$. In step 4 , clinician humility significantly and positively explained additional variance in trust, $\beta=.59, p=<.001 ; F_{(1,100)}=46.85, p<.001$.

Health Status. Results from step 1 indicated that age was a significant predictor of health status, $\beta=-.26, p=.006$; patient gender (being male) also predicted health status, $\beta=.23, p=$ .009 ; as well as patients' insurance type (employer provided compared to all other types), $\beta=$ $.20, p=.02 ; F_{(6,118)}=3.13, p=.007$. In step 2 , clinician characteristic did not account for additional variance in patient's health status, $F_{(4,114)}=.51, p=.73$. In step 3 , visits for acute and preventative issues (compared to chronic issues) significantly explained additional variance in patient's health status, $\beta \mathrm{s}=.55, p<.001 ; F_{(5,109)}=.6 .47, p<001$. In step 4 , clinician humility did not explain additional variance in health status but it was trending in the predicted direction, $\beta=.15, p=.08, F_{(1,108)}=3.01, p=.08$.

\section{Study 2}

Study 1 provided evidence for clinician humility's ability to predict patient outcomes (i.e., patient satisfaction and trust, but not health status). However, Study 1 employed a relatively small sample of undergraduate students recruited through convenience sampling. Although the student sample was diverse in age and race/ethnicity, the results may not generalize to other 
populations. To address this limitation, Study 2 attempted to extend findings from Study 1 by employing a large, community sample through a crowdsourcing website.

\subsection{Method}

3.1.1 Participants. Participants were recruited on Amazon Mechanical Turk (mTurk), an online workforce where people sign up to complete tasks posted by other people. MTurk participants are more diverse than typical participants from convenience sampling [31], which is advantageous for health psychology research because it enables the recruitment of representative community samples. Additionally, mTurk participants' performance on study tasks are similar to or better than subjects who complete studies in person [32]. To focus responses to a general healthcare framework, participants must reside in the United States of America.

Participants received a modest fee for attempting the study. We excluded 53 people from the final analyses because they only answered one or two questions in the survey. We were unable to determine whether they differed from the rest of the sample in any systematic way because they did not provide enough information. The final sample consisted of 361 participants (see Table 1 for complete demographics).

3.1.2 Measures. We employed the same measurements for humility, patient satisfaction, trust, and health status from Study 1. See Table 2 for means, standard deviations, and reliability $(\alpha)$ for these measures. Refer to Table 3 for a summary of descriptive statistics on patient demographic, clinician characteristics, and visit features.

3.1.3 Procedures. Procedures for this study were identical to Study 1. Similar to Study 1, the majority of participants saw a physician (86.9\%); fewer people reported seeing a nurse practitioner $(8.9 \%)$ and physician assistant (4.2\%). On average, these participants took 12.07 minutes $(S D=6.03)$ to complete the survey. 


\subsection{Results}

3.2.1 Data Analysis Plan and Preliminary Analyses. Data analysis plan was identical

to Study 1. Before beginning our primary analyses, we tested the main assumptions for multiple regression. We found no univariate outliers (all $z$-scores were below +/- 2.85) and no multivariate outliers (all Mahalanobis distance scores were below 14.00, $d f=3, \alpha=.001$ ). The highest variance inflation factor (VIF) value was 4.42, suggesting that collinearity was not an issue. Moreover, the histogram of standardized residuals, the P-P plot, and the residual scatter plot supported the normality, linearity, and homoscedasticity assumptions.

3.2.2 Main Results. We organized the main findings by dependent variable below. See Table 5 for a summary of variance accounted for $\left(R^{2}\right.$ and $\left.\Delta R^{2}\right)$.

Patient satisfaction. Results from step 1 indicated that SES predicted patient satisfaction, $\beta=.14, p=.02$; being male predicted satisfaction, $\beta=-.15, p=.01$; insurance status (employer provided insurance compared to all others) also predicted satisfaction, $\beta=.14, p=.02 ; F_{(6,324)}=$ $4.70, p<.001$. In step 2 , clinician characteristics did not account for any additional variance in patient satisfaction, $F_{(4,320)}=1.18, p=.32$. In step 3, wait time significantly accounted for additional variance in patient satisfaction, $\beta=-.19, p=.001 ; F_{(5,315)}=3.63, p=.003$. In step 4, clinician humility significantly and positively explained yet additional variance in patient satisfaction, $\beta=.51, p=<.001 ; F_{(1,314)}=117.72, p<.001$.

Trust. Results from step 1 indicated that SES significantly predicted trust, $\beta=.16, p=$ $.008 ; F_{(6,320)}=2.84, p=.01$. In step 2 , relationship length with the clinician significantly explained additional variance in trust, $\beta=.15, p=.043 ; F_{(4,316)}=3.07, p=.02$. In step 3, days since visit explained additional variance in trust, $\beta=-.12, p=.03 ; F_{(5,311)}=03, p=.04$. In step 4, 
clinician humility significantly and positively explained additional variance in trust, $\beta=.59, p=$ $<.001, F_{(1,310)}=168.13, p<.001$.

Health status. Results from step 1 indicated that SES was a significant predictor of health status, $\beta=.24, p<.001$; age was also a significant predictor of health status, $\beta=-16, p=.003$; $F_{(6,328)}=7.53, p<.001$. In step 2, professional title (physician compared to physician assistant or nurse practitioner) predicted health status, $\beta=.13, p=.02 ; F_{(4,1.67)}=1.68, p=.16$. In step 3, no variable explained health status, $F_{(5,319)}=1.61, p=.16$. In step 4 , clinician humility significantly and positively explained additional variance in health status, $\beta=.29, p<.001, F_{(1,318)}=40.95, p$ $<.001$.

\section{Discussion and Conclusion}

\subsection{Discussion}

Clinician humility is an important construct to study because of its potential to affect patient outcomes. This is the first paper to examine patient perceptions of clinician humility and its relationship with patient outcomes. In two studies, we found that clinician humility consistently predicted patient satisfaction and trust above and beyond the effects of patient demographics, clinician characteristics, and visit features. In addition, we found that clinician humility predicted patient-reported health status in the community sample, but not the student sample.

The finding that humility supports patient satisfaction appropriately reflects the shifting trend in patient care. As the model of care has shifted from a paternalistic model to a more balanced partnership approach, patients expect their clinicians to listen and care for them as whole individuals. Humble clinicians may be effective at these tasks because they seek out ways for patients to be involved in the process of care and they focus on the patients and not 
themselves. Thus, humble clinicians may present more behaviors that patients find more appealing, such as asking open-ended questions and involve patients in decision making $[20,32,33]$.

In addition, humble clinicians have an accurate self-view and are open to new ideas [12], which prevent them from being defensive over patient questions or concerns. Instead of viewing patient questions or concerns about treatment recommendations as threats to their competency or authority [34], humble clinicians view these questions as legitimate concerns that are worthy of consideration. This attentiveness stemming from clinicians' low ego defense may lead patients to feel respected and carefully cared for, which can lead to satisfaction with the care provided.

The finding of clinician humility positively predicting trust is also consistent with the literature. When clinicians are humble, they are aware of their own strengths and weaknesses [12]. Paradoxically, patients trust their clinicians more when clinicians display their potential shortcomings. For example, patient satisfaction and trust increased when doctors shared visit notes with their patients, even when doctors believed the notes contained documentation errors and that patients would disagree with the notes [35]. However, this acknowledgement may lead to a lower perception of the clinician's competency. This contradiction may reflect the conflict in affect-based trust, which is driven by emotional bonds, compared to cognition-based trust, which is based on rational evaluations of competency [36]. Affect-based trust may be more effective than cognition based trust for building effective interpersonal cooperation [37]. In light of these findings, clinicians can present humility and still build trusting relationships.

In addition to building trust via understanding ones' own strengths and weaknesses, humble clinicians may engender trust by being open to new ideas and information and by holding egalitarian beliefs. These characteristics enable clinicians to engage patients as partners 
in the process of care; humble clinicians may recognize that although they are the medical expert, patients are experts about themselves [19]. By recognizing that patients have useful knowledge to share, even if that knowledge counters what the clinician believes, the humble clinician can build a more trusting and effective relationship.

We did not find consistent support for our prediction that clinician humility would predict health status. Using the large community sample in Study 2, we found that clinician humility positively and significantly predicted health status above and beyond the predictive power of patient, clinician, and visit characteristics. However, using undergraduate student participants in Study 1, we did not find this significant effect, although it was trending in the predicted direction. The most prudent explanation for this inconsistency is the difference in sample sizes between the two studies. Study 2's large sample size is superior for detecting significance compared to Study 1's sample size. In addition, demographic differences between the two samples may have contributed this disparity. For example, the community sample was older and was more likely to report chronic health issues as the reason for their visit than the student sample. Moreover, the community sample on average also had longer established relationships with their care provider than the student sample. This relationship length may allow for more opportunities for interaction and evaluation of clinician humility. Ultimately, the inconsistent health status finding highlights the complex relationship between clinician humility and patient outcomes, and warrants further investigation.

\subsection{Limitations/Future Directions}

The samples' demographics present as a limitation to the studies. Our community sample comprised of primarily white men and women, whereas the student sample comprised of mostly Hispanic women. Participants in both samples were primarily insured and an overwhelming 
majority of them have had some of college education. These factors may limit the study's conclusions because the findings may not generalize to all potential healthcare recipients.

Another limitation of the studies is the reliance on patient-reported data. Although clinician humility may be best captured through patient perceptions, it may be most productive to compare these perceptions against objective patient outcomes (e.g., objective health, adherence). By using patient reports in a cross-sectional design, it is impossible to determine the direction of causality. Future studies can address these limitations by employing experimental or longitudinal designs, with special emphasis on objective measures of patient outcomes.

Another limitation is that participants self-selected into our study. Because participation was voluntary and involved recall with a past a medical visit, participants who self-selected to be in the study may be motivated to share their experience for one reason or another. Therefore, these recalled experiences may not represent typical medical visits. Future directions may include collecting perceived humility ratings after an immediate actual visit with a healthcare provider, rather than requiring participants to remember a previous visit. Self-report data is usually the best way to collect this type of data, but interviews and observations in these situations may shed new light on doctor-patient relationships. In addition, studying the atmosphere of the entire office, rather than simply the demeanor of the clinician, may contribute to patient satisfaction. It is likely that humble, caring clinicians require office staff, nurses, and technicians to act in a caring way as well, and the entire environment may be more predictive of patient outcomes rather than the behavior of one person (the clinician).

\subsection{Practice Implications}

Historically, American society has given clinicians a high status, and many clinicians play that role well. However, research on humility and humble clinicians shows that a more 
equal relationship between clinicians and patients may serve patients better. The results from the current studies indicate that clinician humility may be an important factor in predicting patient trust and satisfaction, and potentially patient health status.

Just as the physician-patient relationship is constantly evolving, patient demographics are continually changing. Humble clinicians may be adept at addressing disparities that result from patient race/ethnicity, socioeconomic status, and other social determinants of health. For example, humble clinicians may be able to anticipate shortcomings of patient care due to cultural differences. Humility may lead clinicians to focus on others and to display a lack of superiority toward individuals from different backgrounds and who have different experiences [38].

Based on these findings, if engendering patient satisfaction and trust are important to the practicing clinician [39], they may want to focus on humility and discover strategies to cultivate it. Clinicians may look to established interventions for temporary boosts in humility $[9,40]$. Ultimately, clinicians may be able to become humble by being aware of their own strengths and weaknesses and to value and focus on the potential contribution of their patients. 


\section{References}

1. Crigger, N., \& Godfrey, N.. The importance of being humble. Adv. in Nurs. Scie., 33 (2010) 310-319. https://doi.org/10.1097/ANS.0b013e3181fb2e8c

2. Garchar, K. Imperfection, practice and humility in clinical ethics. J of Eva. in Cli. Pra., 18 (2012) 1051-1056. https://doi.org/10.1111/j.1365-2753.2012.01916.x

3. Gruppen, L. D. Humility and respect: Core values in medical education. Med. Edu. 48 (2014) 53-58. https://doi.org/10.1111/medu.12269

4. Goodyear-Smith, F., \& Buetow, S. Power issues in the doctor-patient relationship. Hea. C Ana, 9 (2001) 449-462. https://doi.org/10.1023/A:1013812802937

5. Chancellor, J., \& Lyubomirsky, S. Humble beginnings: Current trends, state perspectives, and hallmarks of humility. Soc. \& Pers. Psyc. Comp. 7 (2013) 819-833. https://doi.org/10.1111/spc3.12069

6. Wright, J. C., Nadelhoffer, T., Perini, T., Langville, A., Echols, M., \& Venezia, K. The psychological significance of humility. J of Pos. Psyc. 12 (2017) 3-12. https://doi.org/10.1080/17439760.2016.1167940

7. Hilbig, B. E., \& Zettler, I. Pillars of cooperation: Honesty-Humility, social value orientations, and economic behavior. J of Res. in Pers. 43 (2009) 516-519. https://doi.org/10.1016/j.jrp.2009.01.003

8. Davis, D. E., Jr, E. L. W., Hook, J. N., Emmons, R. A., Hill, P. C., Bollinger, R. A., \& Tongeren, D. R. V. Humility and the development and repair of social bonds: Two longitudinal studies. Self \& Id. 12 (2013) 58-77. https://doi.org/10.1080/15298868.2011.636509 
9. Kruse, E., Chancellor, J., Ruberton, P. M., \& Lyubomirsky, S. An upward spiral between gratitude and humility. Soc. Psy. \& Pers. Sci. 5 (2014) 805-814. https://doi.org/10.1177/1948550614534700

10. Twenge, J. M. Generation me - revised and updated: Why today's young Americans are more confident, assertive, entitled--and more miserable than ever before. Simon and Schuster, 2014.

11. de Vries, R. E., \& van Gelder, J. L. Explaining workplace delinquency: The role of HonestyHumility, ethical culture, and employee surveillance. Pers. \& Indi. Diff. 86 (2015) 112116. doi.org/10.1016/j.paid.2015.06.008

12. Ruberton, P. M., Huynh, H. P., Miller, T. A., Kruse, E., Chancellor, J., \& Lyubomirsky, S. The relationship between physician humility, physician-patient communication, and patient health. Pat. Edu. \& Cou. 99 (2016) 1138-1145. https://doi.org/10.1016/j.pec.2016.01.012

13. Tangney, J. P. Humility: Theoretical perspectives, empirical findings and directions for future research. J of Soc. \& Clin. Psych. 19 (2000) 70-82. https://doi.org/10.1521/jscp.2000.19.1.70

14. Funder, D. C. On the accuracy of personality judgment: A realistic approach. Psych. Rev. 102 (1995) 652-670.

15. Sitzia, J., \& Wood, N. Patient satisfaction: A review of issues and concepts. Soc. Sci. \& Med. 45 (1997) 1829-1843.

16. Weiss, B. D., \& Senf, J. H. Patient satisfaction survey instrument for use in health maintenance organizations. Med. Care 28 (1990) 434-445. 
17. Barbosa, C. D., Balp, M.-M., Kulich, K., Germain, N., \& Rofail, D. A literature review to explore the link between treatment satisfaction and adherence, compliance, and persistence. Pat. Pre. \& Adh. 6 (2012) 39-48. https://doi.org/10.2147/PPA.S24752

18. Miller, W. R., \& Rollnick, S. Motivational interviewing: Helping people change. Guilford Press, 2012.

19. Charles, C., Gafni, A., \& Whelan, T. Shared decision-making in the medical encounter: What does it mean? (or it takes at least two to tango). Soc. Sci. \& Med. 44 (1997) 681-692. https://doi.org/10.1016/S0277-9536(96)00221-3

20. Veilleux, S., Noiseux, I., Lachapelle, N., Kohen, R., Vachon, L., Guay, B. W., Bitton, A., \& Rioux, J. D. Patients' perception of their involvement in shared treatment decision making: Key factors in the treatment of inflammatory bowel disease. Pat. Edu. \& Cou. (2018) 101, 331-339. http://dx.doi.org/10.1016/j.pec.2017.07.028

21. Hall, M. A., Dugan, E., Zheng, B., \& Mishra, A. K. Trust in physicians and medical institutions: What is it, can it be measured, and does it matter? Mil. Qua. 79 (2001) 613639, v.

22. Martin, L. R., Feig, C., Maksoudian, C. R., Wysong, K., \& Faasse, K. A perspective on nonadherence to drug therapy: Psychological barriers and strategies to overcome nonadherence. Pat. Pre. \& Adh. 12 (2018) 1527-1535. doi:10.2147/PPA.S155971

23. Idler, E. \& Cartwright, K. What do we rate when we rate our health? Decomposing agerelated contributions to self-rated health. J of Hea. \& Soc. Beh. 59 (2018) 74-93. https://doi.org/10.1177/0022146517750137 
24. Rumsfeld, J., Alexander, K., Goff, D., Graham, M., Ho, M., Masodi, F., ... Zerwich, J. Cardiovascular health: The importance of measuring patient-reported health status. Cir. (2018) 2233-2249.

25. Engel, G. LThe need for a new medical model: A challenge for biomedicine. Sci. 196 (1977) 129-136. https://doi.org/10.1126/science.847460

26. Hawthorne, G., Sansoni, J., Hayes, L., Marosszeky, N., \& Sansoni, E. Measuring patient satisfaction with health care treatment using the Short Assessment of Patient Satisfaction measure delivered superior and robust satisfaction estimates. J of Cli. Epi. 67 (2014) 527-537. https://doi.org/10.1016/j.jclinepi.2013.12.010

27. Anderson, L. A., \& Dedrick, R. F. Development of the Trust in Physician Scale: A measure to assess interpersonal trust in patient-physician relationships. Psych. Rep. 67 (1990) 1091-1100. https://doi.org/10.2466/pr0.1990.67.3f.1091

28. Rabin, R., \& Charro, F. de. EQ-SD: A measure of health status from the EuroQol Group. Ann. of Med. 33 (2001) 337-343. https://doi.org/10.3109/07853890109002087

29. Martin, W. E., \& Bridgmon, K. D. Quantitative and statistical research methods. From hypothesis to results. San Francisco, CA: Wiley \& Sons, Inc., 2012.

30. Tabachnick, D. B., \& Fidell, L.S. Using multivariate statistics ( $5^{\text {th }}$ ed.). Boston, MA: Pearson Allyn \& Bacon, 2007.

31. Casler, K., Bickel, L., \& Hackett, E. Separate but equal? A comparison of participants and data gathered via Amazon's MTurk, social media, and face-to-face behavioral testing. Comp. in Hum. Beh. 29 (2013) 2156-2160. https://doi.org/10.1016/j.chb.2013.05.009 
32. Haskard Zolnierek, K. B., \& DiMatteo, M. R. Physician communication and patient adherence to treatment: A meta-analysis. Med. Care 47 (2009) 826-834. https://doi.org/10.1097/MLR.0b013e31819a5acc

33. Robinson, J. D., \& Heritage, J. Physicians' opening questions and patients' satisfaction. Pat. Edu. \& Cou. 60 (2006) 279-285. https://doi.org/10.1016/j.pec.2005.11.009

34. Gallagher, S. M. Paternalism in healthcare decision making. Ost./Wou. Man. 44 (1998) 22, $24-25$.

35. Bell, S.K., Mejilla, R., Anselmo, M., Darer, J.D., Elmore, J.G., Leveille, S., Ngo, L., Ralston, J.D., Delbanco, T. \& Walker, J. When doctors share visit notes with patients: a study of patient and doctor perceptions of documentation errors, safety opportunities and the patient-doctor relationship. BMJ Qual Saf, 26 (2017) 262-270.

36. McAllister, D. J. Affect- and cognition-based trust as foundations for interpersonal cooperation in organizations. Aca. of Man. J. 38 (1995) 24-59. https://doi.org/10.5465/256727

37. Huynh, H., Johnson, C., \& Wehe, H. Humble coaches and their influence on players and teams: The mediating role of affect-based (but not cognition-based) trust. Psyc Rep., doi: $10.1177 / 0033294119839028$

38. Hook, J.N., Davis, D.E., Owen, J., Worthington Jr, E.L. \& Utsey, S.O. Cultural humility: Measuring openness to culturally diverse clients. J. Coun. Psy. 60 (2013) 353-366. doi:10.1037/a0032595

39. Huynh, H.P. \& Sweeny, K. Clinician styles of care: Transforming patient care at the intersection of leadership and medicine. J. Hea. Psy. 19 (2014) 1459-1470. https://doi.org/10.1177/1359105313493650 
40. Stellar, J.E., Gordon, A., Anderson, C.L., Piff, P.K., McNeil, G.D. \& Keltner, D. Awe and humility. J. Per \& Soc. Psy. 114 (2018) 258-269. http://dx.doi.org/10.1037/pspi0000109 
Table 1

\section{Demographics}

Characteristic mTurk Sample College Students

Total N

Age

Subjective SES
361

Mean (SD)

Mean (SD)
40.4 (11.69)

5.05 (1.67)
136

$25.85(8.53)$

$5.98(1.51)$

$\%$

Gender

Race/Ethnicity

$\begin{array}{lll}\text { Male } & 50 & 20 \\ \text { Female } & 46 & 79 \\ \text { Did Not Indicate } & 4 & 1\end{array}$

White/Caucasian 74

25.5

Black/African American

9.1

6.9

Asian/Pacific Islander

6.6

1.4

Hispanic/Latino

2.9

56.6

Other

1.5

2.1

Mixed

2.5

6.2

Did Not Indicate

3.4

1.3

Education

Insurance Status

$\begin{array}{lll}\text { Some HS/No Diploma } & 1.1 & \text { N/A } \\ \text { HS Diploma/GED } & 8.6 & \text { N/A } \\ \text { Some College/No Degree } & 17.2 & 44.8 \\ \text { Associate Degree } & 13.9 & 49 \\ \text { Bachelor's Degree } & 41.3 & 4.8 \\ \text { Master's Degree } & 12.2 & 0 \\ \text { Doctorate Degree } & 2.2 & 0 \\ \text { Did Not Indicate } & 3.6 & 1.6\end{array}$

Employer Provided

60.1

42.8

Non-Group/Individual Plan

10.2

12.7

4.1

Medicaid

6.6

6.9

Medicare

0

Other Public

3.9

8.3

Uninsured

1.7

6.9

Other

4.7

15.2

15.2

Did Not Indicate 
Table 2

Summary of Measures Used

Measure mTurk Sample

College Students

\begin{tabular}{lccccccc} 
& \# of Items & $\alpha$ & $M$ & $S D$ & $\alpha$ & & \multicolumn{2}{c}{$S D$} \\
\hline Relational Humility & 5 & .97 & 4.05 & .93 & .96 & 4.09 & .88 \\
Trust & 11 & .94 & 5.56 & 1.14 & .94 & 5.27 & 1.25 \\
Satisfaction & 5 & .95 & 4.28 & .82 & .96 & 4.06 & 1.01
\end{tabular}


Table 3

Clinician and Visit Characteristics

$\underline{\text { Clinician Characteristics }}$ mTurk Sample $\quad(n=361) \quad$ College Students $(n=136)$

Gender (\%)

$\begin{array}{lll}\text { Female } & 52.1 & 44.9 \\ \text { Male } & 47.9 & 47.8 \\ \text { Did Not Indicate } & 0 & 7.3\end{array}$

Race/Ethnicity (\%)

$\begin{array}{lll}\text { White/Caucasian } & 73.7 & 47.8 \\ \text { Black/African American } & 5.8 & 7.4 \\ \text { Asian/Pacific Islander } & 12.2 & 7.4 \\ \text { Hispanic/Latino } & 4.2 & 27.9 \\ \text { Other } & 4.1 & 9.5\end{array}$

Professional Title (\%)

$\begin{array}{lll}\text { Physician } & 86.9 & 79.4 \\ \text { Physician Assistant } & 4.2 & 11 \\ \text { Nurse Practitioner } & 8.9 & 9.6\end{array}$

$\underline{\text { Visit Characteristic }}$ mTurk Sample $(n=361) \quad$ College Students $(n=136)$

Purpose of Visit (\%)

$\begin{array}{lll}\text { Preventative } & 48.8 & 44.9 \\ \text { Acute } & 32.1 & 34.6 \\ \text { Chronic } & 11.6 & 8.1 \\ \text { Other } & 7.5 & 12.4\end{array}$

Other Features $[M(S D)]$

Relationship Length (years) 3.54 (4.22) 2.01 (3.06)

Elapsed Time Since

Visit (days) $\quad 79.60$ (96.03) $\quad 84.64$ (111.66)

Wait Time During Visit

$\begin{array}{lll}\text { (minutes) } & 18.47(14.99) & 27.39(29.80)\end{array}$ 
Table 4

Summary of Hierarchical Multiple Regression Analyses, Predicting Patient Outcomes from Clinician Humility for Study 1

\begin{tabular}{|c|c|c|c|c|c|c|}
\hline \multirow[b]{2}{*}{ Predictor } & \multicolumn{2}{|c|}{ Patient Satisfaction } & \multicolumn{2}{|c|}{ Trust } & \multicolumn{2}{|c|}{ Current Health } \\
\hline & $R^{2}$ & $\Delta R^{2}$ & $R^{2}$ & $\Delta R^{2}$ & $R^{2}$ & $\Delta R^{2}$ \\
\hline \multicolumn{7}{|l|}{ Step 1} \\
\hline Patient Characteristics & .02 & .02 & .05 & .05 & .14 & $.14^{* *}$ \\
\hline \multicolumn{7}{|l|}{ Step 2} \\
\hline Physician Characteristics & .08 & .06 & .16 & $.12 * *$ & .15 & .02 \\
\hline \multicolumn{7}{|l|}{ Step 3} \\
\hline Visit Features & .20 & $.12 *$ & .20 & .04 & .34 & $.19 * * *$ \\
\hline \multicolumn{7}{|l|}{ Step 4} \\
\hline Physician Humility & .46 & $.26 * * *$ & .45 & $.37 * * *$ & .36 & .02 \\
\hline$N$ & \multicolumn{2}{|c|}{122} & \multicolumn{2}{|c|}{117} & \multicolumn{2}{|c|}{125} \\
\hline
\end{tabular}

Note: $* \mathrm{p}<05, * * p<.01, * * * p<.001$ 
Table 5

Summary of Hierarchical Multiple Regression Analyses, Predicting Patient Outcomes from Physician Humility for Study 2

\begin{tabular}{|c|c|c|c|c|c|c|}
\hline \multirow[b]{2}{*}{ Predictor } & \multicolumn{2}{|c|}{ Patient Satisfaction } & \multicolumn{2}{|c|}{ Trust } & \multicolumn{2}{|c|}{ Current Health } \\
\hline & $R^{2}$ & $\Delta R^{2}$ & $R^{2}$ & $\Delta R^{2}$ & $R^{2}$ & $\Delta R^{2}$ \\
\hline \multicolumn{7}{|l|}{ Step 1} \\
\hline Patient Characteristics & .08 & $.08 * * *$ & .05 & $.05^{*}$ & .12 & $.12 * *$ \\
\hline \multicolumn{7}{|l|}{ Step 2} \\
\hline Physician Characteristics & .09 & .01 & .08 & $.04 *$ & .14 & .02 \\
\hline \multicolumn{7}{|l|}{ Step 3} \\
\hline Visit Features & .14 & $.05 * *$ & .12 & $.03 *$ & .16 & .02 \\
\hline \multicolumn{7}{|l|}{ Step 4} \\
\hline Physician Humility & .38 & $.23 * * *$ & .43 & $.31 * * *$ & .26 & $.10 * * *$ \\
\hline$N$ & \multicolumn{2}{|c|}{331} & \multicolumn{2}{|c|}{327} & \multicolumn{2}{|c|}{335} \\
\hline
\end{tabular}

Note: $* \mathrm{p}<05, * * p<.01, * * * p<.001$ 